\title{
A METHOD OF INBREEDING COTTON
}

\author{
W. W. Gilbert \\ Washington, D. C.
}

In connection with a line of breeding work looking toward the production of strains of wilt disease (Fusarium) resistant cotton of high productivity, sufficiently early to be adapted for use in bollweevil territory and having other desirable qualities of boll and lint, a large number of crosses were made between several of the best large boll varieties used in weevil territory and the two wilt-resistant varieties, Dixie and Dillon, bred by the Bureau of Plant Industry of the U. S. Department of Agriculture. In the $F_{1}$ generation from these crosses, which were planted on land not infected with wilt, a few of the most promising plants were covered with cheesecloth frames to prevent crossing with undesirable plants or plants of other varieties growing in the vicinity. For the $\mathrm{F}_{2}$ generation, however, zilough selections were saved to plant about three acres and these were placed on wilt-infected land in order to eliminate as many as possible of the non-resistant individuals.

For the purpose of testing the effect of inbreeding in preserving and accentuating the quality of wilt-resistance when it appeared and to prevent the loss of this resistance by promiscuous crossing with the non-resistant individuals which would be present, a method of inbreeding was desired which would be less cumbersome than the old bag method and at the same time one that would not interfere with the normal development of the boll. Manifestly it would te impractical to cover several hundred plants with cheesecloth frames and, moreover, it was not possible under the circumstances, as we desired to make notes on the comparative earliness of the plants, and frames have a tendency to increase vegetative growth to an appreciable extent and delay maturity. Furthermore, the method of covering each flower with a paper bag is slow and tedious and the bags must be removed a few days after the bolls have set in order to permit normal development.

The method finally adopted consists in winding the flower-bud loosely with very fine flexible copper wire. The operation is performed when the flower has attained nearly full size but before it has begun to open at the tip. The wire used was No. 26 soft copper, which comes in 260 -foot rolls costing about 20 cents. It can readily be cut up into desired lengths of 6 to 8 inches with a pair of small scissors. 
The flower-bud is held very carefully in the left hand, the bracts of the involucre being turned back with the thumb and finger while one end of the wire is very lightly hooked through the corolla at the thickened portion near the base just enough to hold it, extreme care being taken not to go too deep and thus injure the interior flower parts. The end of the wire thus inserted is allowed to protrude about half an inch and is then turned over with the finger. This part of the operation must be done very carefully to avoid tearing the delicate corolla. With the finger still on the end of the wire

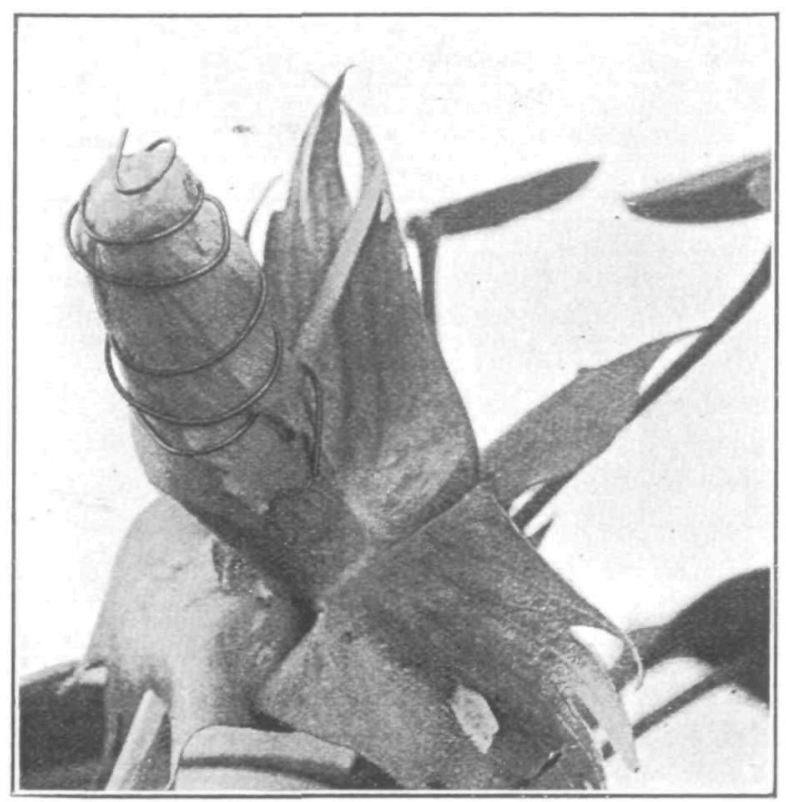

Fig. 1. Copper Wire Method of Inbaredna Cotton Flowers.

Involucre turned back to show method of inserting wire at base of corolla.

the remainder is loosely wound spirally around the flower from base to tip, the spirals at the base being one-fourth to three-eighths of an inch apart and gradually becoming closer and smaller toward the tip until the spiral is closed just above the top of the bud (see fig. 1).

As the cotton flower increases in length very rapidly during the last twenty-four hours before it opens, the buds are not in the best condition to work with until 5 or 6 o'clock of the evening before the day on which they are to open. The work must therefore be 
done after 5 p.m. and before 8 a.m. of the following day since by this time on the morning of a sunny day in July or August the tips of the flowers begin to open sufficiently to allow small insects to enter. Bees have been seen forcing flowers open before this time in the morning and entering to obtain honey.

There is sufficient elasticity to the coiled pliable copper wire to permit the normal development of the flower parts but in no case has a wired flower been seen to open to allow an insect to enter. In fact, the slight growth that takes place after the flowers are wired forces the tip of the corolla into the end of the closed spiral and effectively seals it to the entrance of even the smallest insects.

Slight modifications of this method which were tried before the one above described was hit upon consisted in attaching the end of the wire either to the pedicel of the boll or to the involucre and completing the operation as above given in detail. The method finally chosen has the advantage over these, as over the bag method, that the wire being attached only to the corolla falls with it and leaves the boll to develop normally and it is not necessary to visit the flowers a second time to remove the bags. To mark the selfed bolls a very small white Dennison tag is merely looped over the pedicel of the flower. In case the boll fails to set or is shed later because of unfavoráble weather conditions, or due to subsequent wilt infection of the plant, the tag falls with it and causes no confusion such as would result if the tag were fastened to the limb on which the boll is borne.

After one gets the knack of the operation it can be done very rapidly and with little or no injury to the flowers. First the field is gone over and the best plants are selected and tagged conspicuously with white or bright colored cloths so that they may be readily seen, and then from day to day the flowers are wired and tagged as they reach the right stage of development.

The conditions under which the work was done render the results in percentage of blooms finally harvested not at all comparable with results secured elsewhere where no disease factor is present. In the first place, it is not possible as early as July or the fore part of August, the time when inbreeding must be done, to determine just which plants will later succumb to the wilt disease, since many plants apparently in full vigor in late July are entirely dead by September. Furthermore neither the size of boll nor the length of lint can be determined at this time, as no bolls are matured. It is therefore necessary to select a large number of what then appear to be the most vigorous, productive, wilt-resistant and otherwise desirable 
plants and make a very much larger number of inbreeds than are eventually desired. Hence the necessity for a rapid method.

In 1910, 1377 blossoms on 170 plants were inbred by the copperwire method. After taking into account the considerable number of selected plants that were later killed or stunted by the wilt, and all the inbred bolls on each of these plants, sometimes as many as a dozen, the even larger number of plants eventually discarded because of too small bolls or too short lint, the final harvest of 357 bolls was made from 105 plants. In other words 26 per cent of the original number of flowers wired produced bolls, which were harvested. But 65 plants were discarded altogether, and estimating the number of

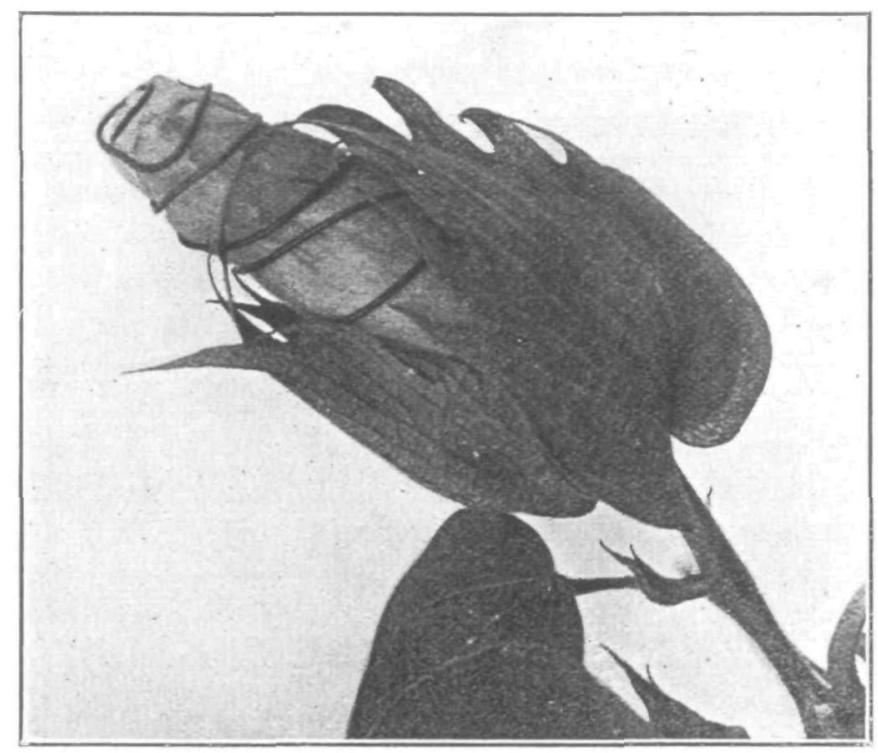

Fro. 2. Wibed Corolla on Cotron Flower with Involdcre Returned to Normal Position.

wired flowers on each of these to be equal to those on the plants saved, there were but 853 flowers wired on the 105 plants finally saved, and 357 of these, or 42 per cent, produced bolls. No record was kept of the total number of bolls which finally matured on wilted and discarded plants.

In comparison with these figures Mr. F. L. Lewton of the Office of Cotton Breeding, Bureau of Plant Industry, advises me that in some inbreeding work at Yuma, Arizona, he secured about 50 per cent of sets from flowers merely covered with paper bags, the bags 
being removed a few days after pollination had taken place. There the conditions are very favorable to pollination due to the occurrence of bright, sunny days and the almost entire absence of rain.

Under ordinary conditions in a humid climate the percentage of sets varies with the weather and with the time in the season when the work is done, from a possible 90 per cent in the early part of the blossoming period of the plant and in favorable weather to 10 per cent or less late in the summer and under unfavorable conditions.

Mr. E. C. Ewing of the Mississippi Agricultural Experiment Station has tested the method on a small scale with satisfactory results. He says, "I found it to be thoroughly effective and to require less time than the method of bagging."

\title{
VARIATION IN PURE LINES OF WHEAT
}

\author{
C. G. Williams \\ Wooster, Ohio
}

In 1907 the Ohio Station began some studies of variation in pure lines of wheat. By "pure line" is meant the progeny of a single head. Four characters are being studied. In this progress report two characters only will be considered-protein content and size of kernel.

Variation with respect to protein content.-This test has been carried on with two pure lines; one of Fultz wheat and the other of Poole. In determining the protein content of the heads used in this work, the kernels on one side of the rachis were used, the other half of the head being saved for planting. A preliminary test of 200 heads showed that the variation in the protein content of the two parts of the head when divided in this way was less than one-tenth of 1 per cent.

The initial planting was made in 1907 . The head of Fultz wheat used analyzed 12.92 per cent protein. Of the progeny of this head, 100 good heads were analyzed. Their average protein content was 14.33 per cent. The 10 heads having the highest per cent of protein were chosen for the high protein strain Fultz. The head highest in protein analyzed 20.13 per cent and the 10 highest averaged 16.81 per cent (see table 1, first column). The 10 heads of the 100 having the lowest per cent of protein were chosen for the low protein strain Fultz. The head lowest in protein analyzed 10.38 per cent and the 10 lowest averaged 12.44 per cent. These 20 heads were planted in 1908, a head to a row, the high and low head-rows alternating. 